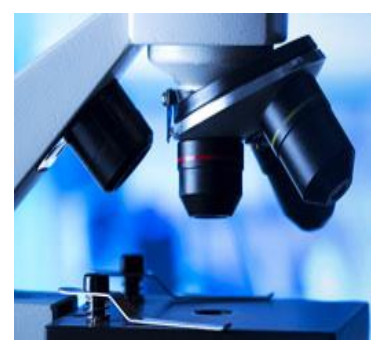

E-ISSN: 2707-4455

P-ISSN: 2707-4447

www.forensicpaper.com/

IJFM 2019; 1(2): 19-21

Received: 18-05-2019

Accepted: 21-06-2019

\section{Dr. Rahul Kumar}

Department of Forensic medicine, R. G. Kar Medical College and Hospital, Kolkata, India
Corresponding Author: Dr. Rahul Kumar

Department of Forensic medicine, R. G. Kar Medical College and Hospital, Kolkata, India

\title{
To assess atherosclerosis related death in population- An autopsy study
}

\section{Dr. Rahul Kumar}

DOI: https://doi.org/10.33545/27074447.2019.v1.i2a.14

\section{Abstract}

Background: Coronary artery atherosclerosis is the main cause of sudden death in India and other countries. The present study was conducted to assess atherosclerosis related death in population.

Materials \& Methods: The present study was conducted on 56 cases of atherosclerosis related deaths of both genders. The time of onset of illness, survival time, and any past history of smoking, hypertension or diabetes was recorded. The routine autopsy technique (Virchow's1) was used for post mortem examination.

Results: Out of 56 patients, males were 32 and females were 24. Maximum cases were of RCA (14) seen in maximally with grade 1 in 7 cases followed by LM (20) with grade 1 in 11, LAD (18) with grade 1 in 12 and LC (6) with grade $2(3)$. The difference was significant $(P<0.05)$. The risk factors was hypertension in 34 , diabetes in 14 , smoking in 20 and tobacco use in 18 cases. The difference was significant $(P<0.05)$.

Conclusion: Authors found that most common cause of death due to atherosclerosis was involvement of left main trunk and hypertension was risk factor.

Keywords: atherosclerosis, smoking, hypertension

\section{Introduction}

Coronary artery atherosclerosis is the main cause of sudden death in India and other countries ${ }^{[1]}$. Since coronary artery atherosclerosis are such a large determinant of morbidity and mortality, it is important to have a knowledge of the structural pathology of heart, for example where the arterial stenosis most frequently occurs, how much of the artery is likely to be affected, how often several arteries are involved, the severity of stenosis of the affected arteries and development and progression of the disease as an age related phenomenon ${ }^{[2]}$.

Sudden death is a death due to natural causes of an individual who was not restricted to his house, hospital, or other institution, or unable to function in the community for more than 24 hours prior to death, and for whom the time interval from onset of the fatal event until death was less than 24 hours. The sudden deaths were divided into several categories according to the time interval from onset until death, whether the death was witnessed or not, and by prior history of the disease causing the death ${ }^{[3]}$.

Various reasons for atherosclerosis includes age, sex, smoking, diet, body weight, physical inactivity, high blood pressure, diabetes and high cholesterol levels ${ }^{[4]}$. The present study was conducted to assess atherosclerosis related death in population.

\section{Materials \& Methods}

The present study was conducted in the department of Forensic Medicine. It comprised of 56 cases of atherosclerosis related deaths of both genders. Ethical clearance was taken prior to the study.

General information such as name, age, gender etc. was recorded. Signs and symptoms suggestive of myocardial ischemia such as chest pain, sweating, collapse and shock was recorded the time of onset of illness, survival time, and any past history of smoking, hypertension or diabetes was recorded. The routine autopsy technique (Virchow's1) was used for post mortem examination. Results thus obtained were subjected to statistical analysis. $\mathrm{P}$ value less than 0.05 was considered significant. 


\section{Results}

Table I: Distribution of patients with coronary heart disease

\begin{tabular}{|c|c|c|}
\hline \multicolumn{3}{|c|}{ Total- 56 } \\
\hline Gender & Males & Females \\
\hline Number & 32 & 24 \\
\hline
\end{tabular}

Table I, graph I shows that out of 56 patients, males were 32 and females were 24 .

Table II: Distribution of cases according to grading of narrowing of coronary artery lumen

\begin{tabular}{|c|c|c|c|c|c|c|}
\hline $\begin{array}{c}\text { Coronary } \\
\text { artery }\end{array}$ & $\begin{array}{c}\text { Grade } \\
\mathbf{0}\end{array}$ & $\begin{array}{c}\text { Grade } \\
\mathbf{1}\end{array}$ & $\begin{array}{c}\text { Grade } \\
\mathbf{2}\end{array}$ & $\begin{array}{c}\text { Grade } \\
\mathbf{3}\end{array}$ & $\begin{array}{c}\text { Grade } \\
\mathbf{4}\end{array}$ & $\begin{array}{c}\text { P } \\
\text { value }\end{array}$ \\
\hline RCA (14) & 2 & 7 & 4 & 1 & 0 & 0.01 \\
\hline LM (20) & 3 & 11 & 3 & 1 & 2 & 0.02 \\
\hline LAD (18) & 1 & 12 & 2 & 1 & 1 & 0.03 \\
\hline LC (6) & 1 & 1 & 3 & 1 & 0 & 0.01 \\
\hline
\end{tabular}

Table II, graph I shows that maximum cases were of RCA (14) seen in maximally with grade 1 in 7 cases followed by LM (20) with grade 1 in 11, LAD (18) with grade 1 in 12 and LC (6) with grade 2 (3). The difference was significant $(P<0.05)$.

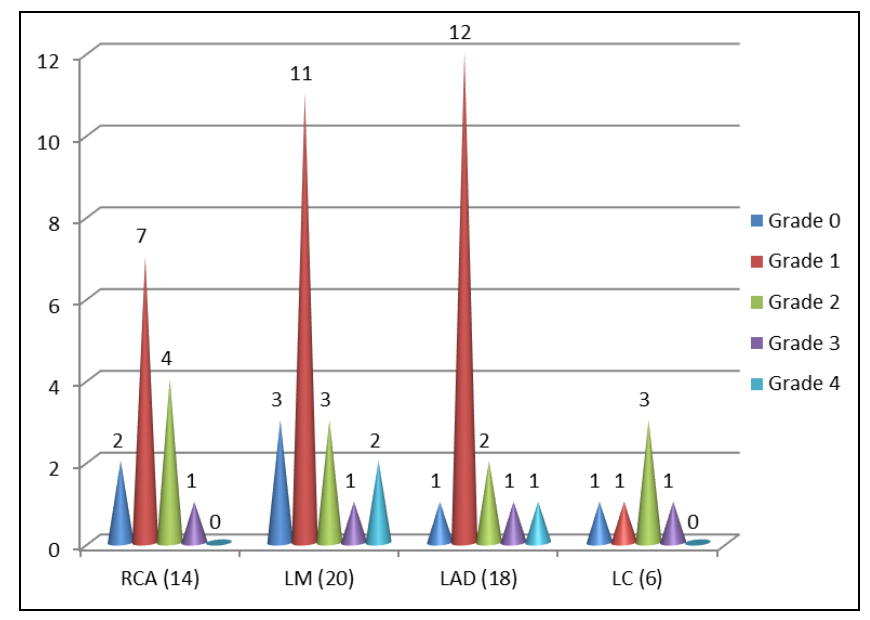

Graph I: Distribution of cases according to grading of narrowing of coronary artery lumen

Table III: Risk factors

\begin{tabular}{|c|c|c|}
\hline Risk factors & Number & \multirow{2}{*}{ P value } \\
\hline Hypertension & 34 & \multirow{2}{*}{0.05} \\
\hline Diabetes & 14 & \\
\hline Smoking & 20 & \\
\hline Tobacco & 18 & \\
\hline
\end{tabular}

Table III shows that risk factors was hypertension in 34, diabetes in 14, smoking in 20 and tobacco use in 18 cases. The difference was significant $(P<0.05)$.

\section{Discussion}

In cases of sudden death, cardiovascular disease (45 to 50\%) was the most important cause of the sudden natural death among population ${ }^{[5]}$. It was followed by respiratory disease (15 to $23 \%$ ), central nervous system disease (10 to 15\%) and others. The medico-legal opinion may be asked about the state of coronary artery in sudden death in road accidents, operations, and occupational diseases ${ }^{[6]}$. Coronary artery disease is responsible for over $70 \%$ of sudden cardiac deaths. In the young, the primary cause of death is the nonatherosclerotic coronary abnormalities. In the older patients; the most prevalent cause is atherosclerotic Coronary disease
[7]. The present study was conducted to assess atherosclerosis related death in population.

In present study, out of 56 patients, males were 32 and females were 24 . Lau et al. ${ }^{[8]}$ found that incidence of coronary artery disease is more in males as compared to females. Most common risk factor observed in death due to coronary artery disease was Hypertension (20.09\%), followed by smoking (14.95\%) and followed by diabetes mellitus (12.62\%). Narrowing of lumen was maximally observed in left anterior descending coronary artery.

We found that maximum cases were of RCA (14) seen in maximally with grade 1 in 7 cases followed by LM (20) with grade 1 in 11, LAD (18) with grade 1 in 12 and LC (6) with grade 2 (3). Maron et al. ${ }^{[9]}$ found that a final coronary episode may sometimes be associated with an operative procedure supposedly due to hypotensive state. During driving or piloting a person may goes into a state of confusion because heart attack. In this state he may lose control and an accident can happen. These conditions indicate that intervention of Forensic Pathologist is significant to decide the actual cause of death apart from injury or disease of vital organs. They examined coronary arteries for atherosclerotic changes in 50 cases of sudden deaths. They observed that there were marked intimal thickening with luminal narrowing $\leq 75 \%$ of luminal diameter in 20 cases $(40 \%)$ in total hearts. In natural deaths 17 cases $(48.57 \%)$ showed luminal narrowing $\leq 75 \%$ of luminal diameter. These findings are suggestive of medico legal intervention to clarify the mode of death in some instances.

We found that risk factors were hypertension in 34 , diabetes in 14, smoking in 20 and tobacco use in 18 cases. It is shown that coronary artery disease is an occupational disease due to prolonged exposure to deleterious substances like carbon disulphide in industries. There are certain occasions, when a person dies on the operating table or soon after surgery, and a coronary attack is probably the cause of death in such cases. A final coronary episode may sometimes be associated with an operative procedure supposedly due to hypotensive state. In such circumstances, the anaesthetic procedure or surgical interference is merely a precipitating factor in already diseased, but silent coronaries ${ }^{[10]}$. Unexplained coronary deaths were found to be eight times more common in surgical than in the medical wards. The shortcoming of the study is small sample size.

\section{Conclusion}

Authors found that most common cause of death due to atherosclerosis was involvement of left main trunk and hypertension was risk factor.

\section{References}

1. Sarkoija T, Hirvoven J. causes of sudden unexpected deaths in young and middle aged persons. FSI. 1984; 24:247-261.

2. Zanjad NP, Nanadkar SD. Study of Sudden Unexpected Deaths in Medico-Legal Autopsies JIAFM, 2006; 28(1):27-30.

3. Derya AA. Sudden deaths in Edirne, Turkey, from 1984 to 2005. Med. Sci. Law. 2007; 47(2):147-155.

4. Puranik R, Clara KC, Dufolu JA, Kilborn MJ, Mcguire MA. Sudden death in young children. The journal of Paediatrics. 1949; (34):166-173. 
5. Gajera CN. Study of histopathological changes in coronary arteries in the autopsy cases done at government medical college / new civil hospital, Surat: Veer Narmad South Gujarat University, 2012.

6. Bambhaniya AB. Study of Coronary Arteries and Myocardium in Sudden Death Cases at Autopsy Jamnagar: Saurashtra University, 2012.

7. Nulcohy R. Medico legal aspect of Coronary heart diseases. The Medico legal J; 1968; 36:87

8. Lau. Ischaemic heart disease as a natural cause of death in Motorists. Singapore Med J. 1994; 35:467-470.

9. Maron BJ, Gohman TE, Aeppli D. Prevalence of sudden cardiac death during competitive sports activities in Minnesota high school atheletes. J. Am. Coll. Cardiol. 1998; 32:1881-1884.

10. Joseph A, Ackerman D, Talley JD, Johnstone J, Kupersmith J. Manifestations of coronary atherosclerosis in young trauma victims-- an autopsy study. J Am Coll Cardiol. 1993; 22(2):459-67 